\title{
Influence of Pavement on Fatigue Performance of Urban Steel Box Girder Deck
}

\author{
Zhongyue $\mathrm{ZHENG}^{1, \mathrm{a}}$, Mian $\mathrm{TANG}^{1, \mathrm{~b}}$ and Shaoquan $\mathrm{LV}^{1, \mathrm{c}}$ \\ ${ }^{1}$ College of Civil Engineering, Central South University Changsha 410075 China \\ a1175982546@qq.com, ${ }^{b} \operatorname{tangmian513@163.com,~}{ }^{c} 294776643 @$ qq.com
}

\begin{abstract}
Based on spatial finite element analysis method, the Influence of pavement on fatigue performance of orthotropic steel deck was analyzed in terms of pavement system, asphalt pavement stiffness. The result shows that compared with asphalt pavement system, RPC pavement system can not only obviously improve the stress condition of steel bridge deck, but also significantly extend the fatigue life of steel bridge panel; Increasing the stiffness of pavement layer can obviously reduce the stress amplitude of fatigue details, especially for direct contact with the pavement.
\end{abstract}

Keywords: Orthotropic plate Pavement Fatigue life Stress amplitude

\section{Introduction}

As the protective layer of steel deck plates, bridge pavement's relative stiffness is large, and its material properties have a large impact on the fatigue properties of the steel deck. Many scholars have conducted research on this issue. Tongji University Chong $\mathrm{Wu}{ }^{[1]}$ adopted ABAQUS finite element program, in large-span cable-stayed bridge and suspension as an example, discussed the effects of elastic modulus, pavement layer thickness and other factors on fatigue stress amplitude of steel deck. Hunan University Dongpo Zhang ${ }^{[2]}$ considered the diaphragm spacing, pavement layer thickness and longitudinal rib height and other parameters, analyzed stress intensity and fatigue properties of crack tip. Since the provisions about fatigue check of steel bridge on China's current bridge design Specifications are relatively backward, and don't have checking fatigue load spectrum, especially lacking of clear design concept for fatigue problems of orthotropic steel deck. it has certain practical significance to discuss the influence of pavement and construction details on the fatigue properties of urban continuous bridge deck.

According to the European norms Eurocode 1, in orthotropic steel box girder of a city overpass as an example, this paper summarized the results of previous studies, made a research on fatigue stress analysis and life assessment of bridge deck, discussed the effects of elastic modulus, pavement layer thickness on fatigue stress amplitude of steel deck.

\section{Project Background}

Some ramp of a city three layer overpass with variable width or high continuous steel box girder bridge, the main span from $25 \mathrm{~m} \sim 50 \mathrm{~m}$, the bridge deck width $7.3 \mathrm{~m} \sim 12.5 \mathrm{~m}$, beam height $1.6 \mathrm{~m} \sim 2.5 \mathrm{~m}$. The NE ramp $(34.3 \mathrm{~m}+34.9 \mathrm{~m})$ this paper selected is two span 
continuous steel box girder bridge using single box section. The center beam is $1.8 \mathrm{~m}$ high. The box girder top plate is $8.14 \mathrm{~m} \sim 7.32 \mathrm{~m}$ wide. The bottom is $3.98 \sim 3.1 \mathrm{~m}$ wide. Steel material is Q345qE. The bridge deck is orthotropic structure. The main section is shown in Figure 1

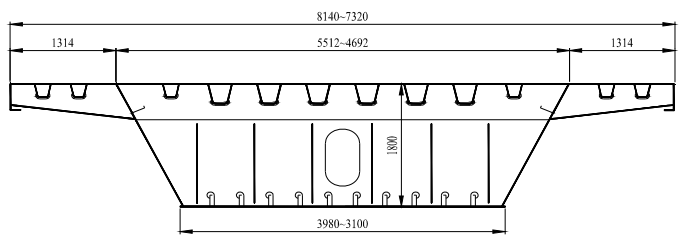

Fig.1 Standard section of NE ramp steel box girder（unit:cm）

\section{Computational Model}

Using ANSYS finite element analysis software to build steel box girder segment model, in order to simulate the stress of orthotropic steel bridge deck under vehicle load, we take 3 diaphragm intervals along the bridge. Steel bridge deck, bottom plate, transverse diaphragm, web and pavement are simulated by shell63 and Solid45 element.

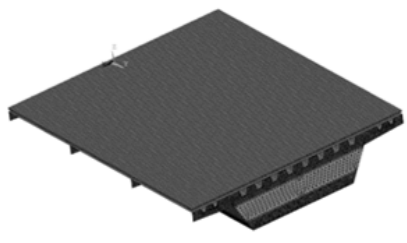

Fig.2FEM of deck pavement

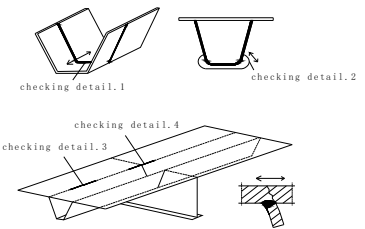

Fig.3 Fatigue checking details

Welded joints of steel deck are relatively easy to crack. The structural details of checking the fatigue strength are mainly.: (1)longitudinal ribs butt weld; (2)the diaphragm web opening edge; (3)longitudinal rib and top plate weld; (4)longitudinal rib and top plate weld located at wed.(Details are shown in Figure 3)

\section{Influence of Pavement System on Fatigue Performance of Steel Deck}

\subsection{Factors affecting the detail stress.}

Asphalt concrete pavement is combined with steel deck by a bonding layer. Because of various reasons, the deck will appear fatigue crack and other diseases. Reactive powder concrete $^{[3]}$ (Reactive Power concrete- referred RPC) used as a new pavement system by Hunan University Xudong Shao ${ }^{[4] \sim 6}$ professor can significantly improve the mechanical behavior of bridge deck. In this paper, the common asphalt pavement and RPC pavement system were compared.

In vehicle loading, it should be to make the checking details maximum stress as the criterion of the most unfavorable loading location. The loading wheel axle load is $100 \mathrm{KN}$, and considering the impact coefficient of 0.15 . The results are shown in Table 1. The details from 1 to 4 selected by this paper are showed in Figure 3. 
TABLE.1 STRESS PEAK OF DIFFERENT PAVEMENT (UNIT: MPA)

\begin{tabular}{cccc}
\hline \multirow{2}{*}{$\begin{array}{c}\text { Pavement } \\
\text { Stress of checking } \\
\text { detail }\end{array}$} & No slip & Asphalt pavement & $\begin{array}{c}\text { RPC } \\
\text { pavement }\end{array}$ \\
\cline { 2 - 4 } Detail.1 & 31.2 & Slip & - \\
\hline $\begin{array}{c}\text { Detail.2 } \\
\text { Detail.3 }\end{array}$ & -35.0 & 33.1 & 23.8 \\
Detail.4 & -32.5 & -36.4 & -27.8 \\
\hline
\end{tabular}

From table1, it can be known that compared with the asphalt pavement system, RPC pavement significantly reduce the stress peak of the checking details, in which the details of 3,4 of the stress peak value of the reduction is far greater than the details 1, 2. RPC pavement system can significantly improve the stress of details 3,4 , which is in directly contact with pavement layer.

\subsection{Life assessment of urban steel bridge deck.}

In order to study conveniently, the load frequency spectrum composed of six kinds of models, which is simplified by Lewei Tong ${ }^{[7]}$ to research the fatigue load of a road bridge in Shanghai, is used for the study. Traffic volume is 10000 / day. The stress history of different pavement system is obtained by loading the six kinds of model car in accordance with the maximum value of the detail stress. According to the rain flow counting method and the traffic volume of each model car, we got the different stress amplitude $\Delta \sigma_{\mathrm{i}}$ and the corresponding number of cycles $N_{i}$. Figure 4, Figure5 shows the stress spectrum of details under the pavement system.
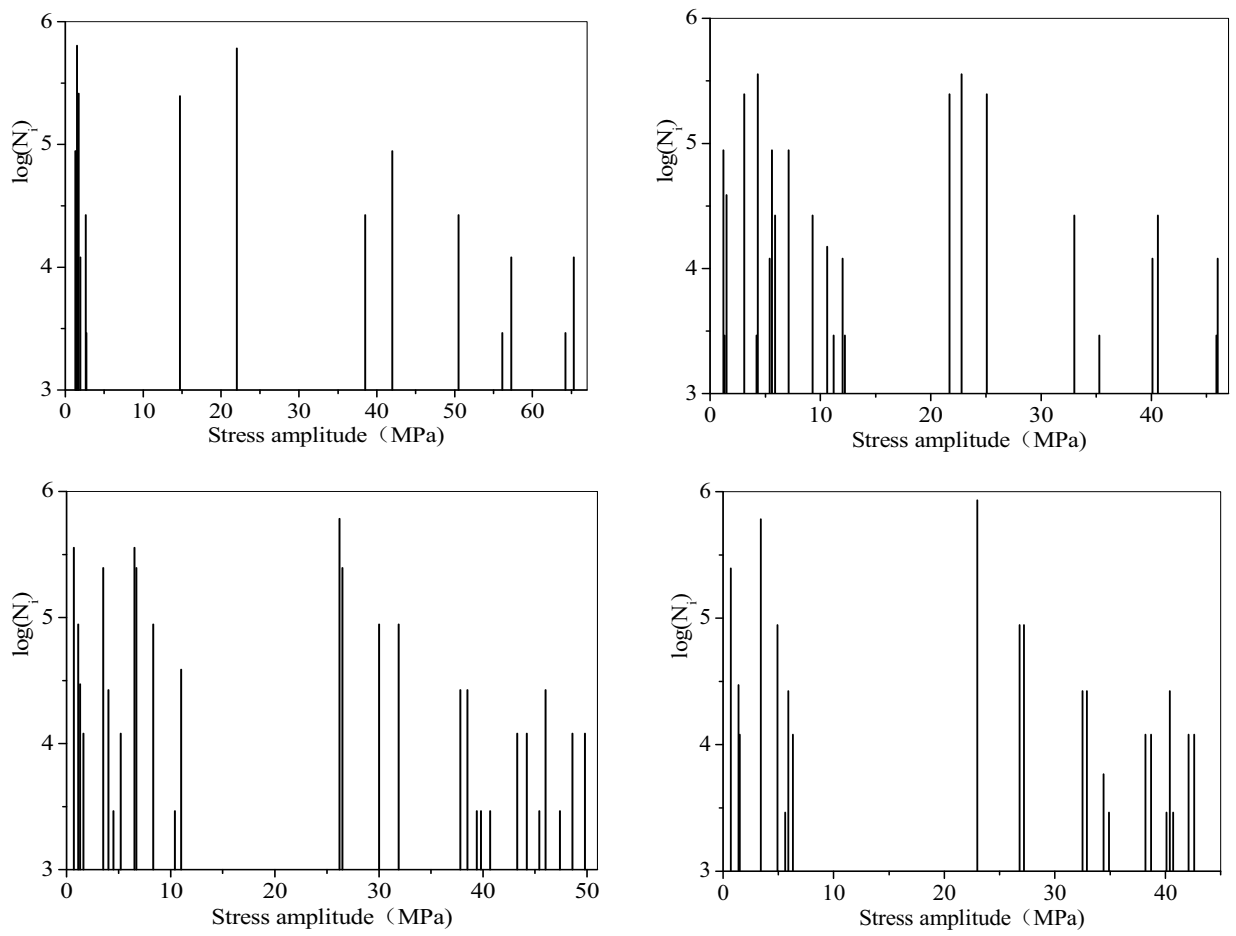

(a) Stress spectrum of detail.1 (b) Stress spectrum of detail.2

(c) Stress spectrum of detail.3 (d) Stress spectrum of detail.4

Fig.4stress spectrum of Asphalt pavement system checking details 

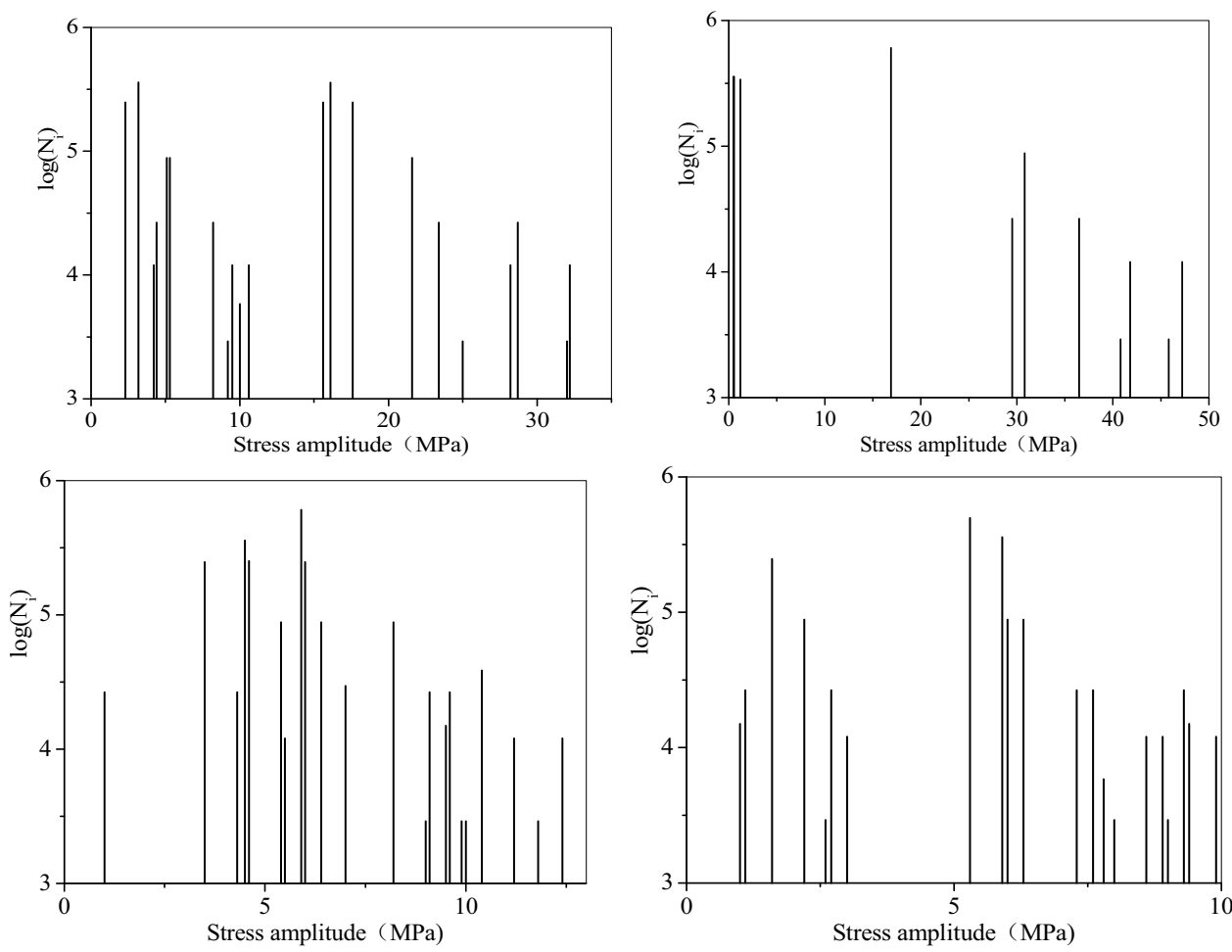

(a) Stress spectrum of detail.1 (b) Stress spectrum of detail.2

(c) Stress spectrum of detail. (d)

Stress spectrum of detail.4

Fig.5 stress spectrum of RPC pavement system checking details

This paper selected the relevant variable amplitude load fatigue strength curve of checking details in the European Eurocode1. From the results of checking details stress spectrum showed by Figure 4, Figure 5, we can know that the maximum stress amplitude of each checking detail is lower than that of the constant amplitude fatigue limit, and each checking details theoretically has unlimited lifetime. Actually, the welding quality and welding residual stress of the welding seam seriously affect the service life of the steel bridge, which is mainly reflected in the influence of the fatigue characteristics and fatigue limit. Therefore, the influence of these factors on the fatigue life of steel bridge can be considered through the reduction of the fatigue limit. Take $\Delta \sigma_{\mathrm{L}}$ and $\Delta \sigma_{\text {cut }}$ reduction factor of 0.5 and calculate the fatigue life of the details under different pavement system. 
TABLE.2 THE FATIGUE LIFE OF DETAILS UNDER DIFFERENT PAVEMENT SYSTEMS (UNIT: MPA)

\begin{tabular}{|c|c|c|c|c|c|c|}
\hline $\begin{array}{c}\text { Detail } \\
\text { Number }\end{array}$ & $\begin{array}{l}\text { Constant } \\
\text { amplitude } \\
\text { fatigue limit } \\
\text { after a } \\
\text { reduction } \\
(\mathrm{MPa})\end{array}$ & $\begin{array}{c}\text { Variable } \\
\text { amplitude } \\
\text { fatigue } \\
\text { limit after } \\
\text { a } \\
\text { reduction } \\
(\mathrm{MPa})\end{array}$ & Pavement & $\begin{array}{c}\text { Maximum } \\
\text { stress } \\
\text { amplitude } \\
(\mathrm{MPa})\end{array}$ & $\begin{array}{l}\text { Years } \\
\text { of } \\
\text { fatigue } \\
\text { damage } \\
\text { degree } \\
\text { D }\end{array}$ & $\begin{array}{l}\text { Fatigue } \\
\text { life } \\
\text { (year) }\end{array}$ \\
\hline \multirow{2}{*}{1} & \multirow{2}{*}{41.6} & \multirow{2}{*}{23.2} & Asphalt & 46 & 0.0166 & 60.2 \\
\hline & & & RPC & 32.2 & 0 & Infinite \\
\hline \multirow{2}{*}{2} & \multirow[b]{2}{*}{ - } & \multirow{2}{*}{ - } & Asphalt & 65.3 & 0 & Infinite \\
\hline & & & RPC & 47.2 & 0 & Infinite \\
\hline \multirow{2}{*}{3} & \multirow{2}{*}{41.6} & \multirow{2}{*}{23.2} & Asphalt & 49.8 & 0.056 & 17.9 \\
\hline & & & RPC & 12.4 & 0 & Infinite \\
\hline 4 & 41.6 & 23.2 & $\begin{array}{c}\text { Asphalt } \\
\text { RPC }\end{array}$ & $\begin{array}{c}42.6 \\
9.9\end{array}$ & $\begin{array}{c}0.021 \\
0\end{array}$ & $\begin{array}{c}45.7 \\
\text { Infinite }\end{array}$ \\
\hline
\end{tabular}

From table 2, it can be known that the life of the details of the asphalt paving system has changed greatly, especially in the details of the longitudinal ribs and the top plate weld. For the RPC pavement system, when there is a problem of weld, the life of the checking details is still unlimited. This shows that the pavement system has a great influence on the fatigue life of the checking details, and RPC pavement system can greatly improve the fatigue life of the steel bridge deck.

\subsection{The Influence of the Stiffness of the Asphalt Pavement on the Stress Amplitude of the Steel Deck}

Asphalt concrete pavement has the advantages of light weight, good adhesion, comfortable driving, convenient maintenance, but the material characteristics of asphalt will be softened with the increase of temperature. The change range of elastic modulus is about $500 \mathrm{MPa} \sim 1500 \mathrm{MPa}$, and the thickness is generally between $40 \mathrm{~mm} \sim 80 \mathrm{~mm}$. Due to the small thickness of the steel bridge deck and the large relative stiffness of the pavement layer, the steel deck in the fatigue design, should take into account the interaction with pavement layer. In this section we selected "Urban bridge design specification" the city -A level vehicle loads (70t) and "Highway bridge design general specification" vehicle load (55t), and considered the influence of elastic modulus and thickness of pavement on steel deck stress amplitude. The results are shown in Figure $6 \sim 7$.
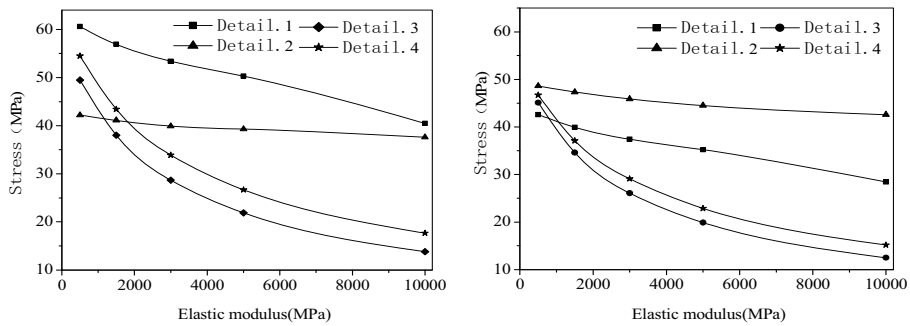
(a) city -A vehicle load
(b) vehicle load in highway regulations

Fig.6 The curve of stress amplitude with Elastic Modulus 
As showed in Fig.6

(1) The stress amplitude of the checking details is about $10 \sim 60 \mathrm{MPa}$, and with the increase of elastic modulus, the stress amplitude variation of the details 3, 4 is obvious, and the details of 1,2 is relatively flat. Thus, the checking details 3,4 which are directly related to bridge deck are more sensitive to the change of the asphalt pavement elastic modulus.

(2) The equivalent stress amplitude of the 1, 3 and 4 under the city -A vehicle load is greater than vehicle load in highway regulations, and the detail 2 is opposite. That is, for the urban bridge, the stress amplitude of longitudinal rib butt weld and the connection weld of longitudinal rib and top plate is higher than highway bridge, and the edge of the diaphragm is opposite.

Most of the pavement thickness of steel bridge deck is about $40 \sim 80 \mathrm{~mm}$, we selected 4 kinds of pavement thickness. The elastic modulus of pavement is 5000MPa. Fig.7 (a), Figure.7 (b) respectively show the graph of equivalent stress amplitude variation with thickness under city-A vehicle loads and vehicle load in highway regulations.

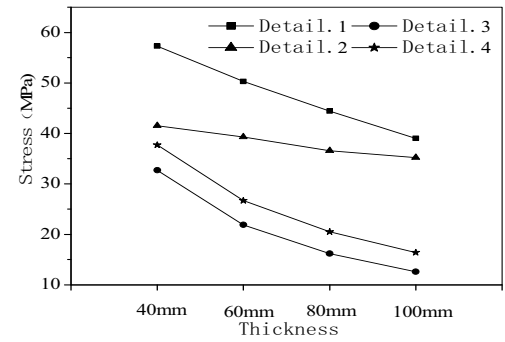

(a) city -A vehicle load

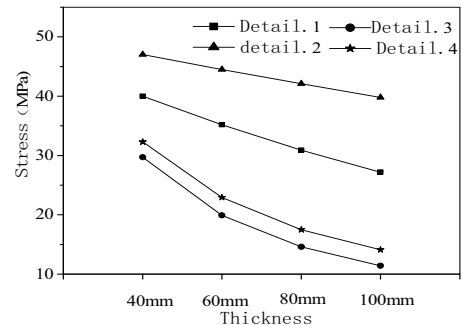

(b) vehicle load in highway regulations

Fig.7 The curve of stress amplitude with Thickness

As showed in Fig.7

(1) The stress amplitude of the checking details is about 10 60MPa, and with the increase of thickness, the stress amplitude variation of the details 3, 4 is obvious, and the details of 1,2 is relatively flat. This shows that the change of pavement thickness has great influence on equivalent stress amplitude of the connection weld of longitudinal rib and top plate than the edge of the diaphragm and longitudinal rib butt weld, but the influence is less than the change of pavement thickness.

(2) Under different thickness of pavement, the effect under the city-A vehicle load and vehicle load in highway regulations on the details of the equivalent stress amplitude is consistent with the influence of different elastic modulus.

\section{Conclusions}

(1) For asphalt pavement system, welding quality, welding residual stress and other factors have a great influence on the life of the steel bridge deck. Improving the adhesion of the bonding layer to the pavement and bridge deck can effectively improve the mechanical properties of the bridge deck. Compared with the asphalt pavement, the new material (RPC) paving system can improve the stress state of the steel deck, reduce the stress of the details, and greatly improve the fatigue life of the steel deck.

(2) The stress amplitude of the steel deck checking details decreases with the increase of elastic modulus and thickness of pavement layer, and improving the stiffness of the pavement layer can effectively reduce the stress amplitude of the checking details which directly contact with pavement layer.

(3) For the connection weld of longitudinal rib and top plate and longitudinal rib butt weld, equivalent stress amplitude under city-A vehicle loads is more than vehicle load in 
highway regulations, and diaphragm opening edge is opposite. The reason is that the stress influence line is longer, longitudinal wheelbase and corresponding axle load of the vehicle load has great effect on its value.

\section{References}

1. Chong $\mathrm{Wu}$, Haiyan Liu. Influence of pavement on fatigue stress range of orthotropic steel deck[J]. Engineering Sciences, 2010,12(7):39-42.

2. Dongpo Zhang. Fatigue properties study of orthotropic steel bridge deck[D].Hunan Uiversity. 2012

3. Richard P, Cheyrezy M. Composition of reactive powder concretes[J]. Cement and concrete research, 1995, 25(7): 1501-1511.

4. Xudong Shao, Junhui Cao, Dutao Yi. Research on basic performance of composite bridge deck system with orthotropic steel deck and thin RPC layer[J].China Journal Highway and Transport, 2012, 25(2): 40-45.

5. Bin Chen, Xudong Shao, Junhui Chao. Study of fatigue cracking for orthotropic steel bridge deck[J]. Engineering Mechanics, 2012, 29(12): 170-174.

6. Jia Li, Xiaotian Feng, Xudong Shao. Research on composite paving system with orthotropic steel bridge deck and thin RPC layer[J]. Journal of Hunan University(Natural Sciences), 2013, 39(12): 7-12.

7. Lewei Tong, Zuyan Shen. Fatigue load spectrum for urban roads and bridges[J].Journal of civil engineering , 1997, 30(5): 20-27. 